\title{
Minor Elements Recovery and Impurity Control in Industrial Metal Processing
}

Michael Free

Minor elements can play a significant role in metal processing. Although small in quantity, some elements can lead to modifications in process flow sheets in order to meet product purity requirements, environmental regulations, or to facilitate greater revenue. In some processing streams precious metals are present as minor elements, yet in some scenarios such as copper porphyry deposits, they can be keys to process economics. Elements such as arsenic and selenium are critical from an environmental perspective and need to be controlled and removed from process streams. Impurity elements are the primary reason for electrorefining, and the effectiveness of their removal determines the final product purity.

\section{Precious Element Recovery}

Precious metals such as gold and platinum are recovered primarily from ores. However, a substantial portion of precious metals that are in use today are recovered as by-products from industrial metal processing or from recycling. Rio Tinto's Kennecott operation at Bingham Canyon produces 400,000 ounces of gold as a by-product of producing 300,000 tons of copper each year. ${ }^{1}$ The gold production at this facility would not be economically feasible without copper production as the primary metal. Silver is also a byproduct at Kennecott's facility with approximately 4 million ounces of annual production. Similarly, production of precious elements as by-products from industrial metal processing is common. Precious elements such as rhenium are also present in process streams. The high value of rhenium makes it economic to recover relatively small amounts.

\section{Rare Element Recovery}

Many of the elements that are critical to specific needs in society are available because of their production as by-products of industrial metal processing. The primary supply of elements such as bismuth, cadmium, gallium, indium, and tellurium is based on by-product recovery. Bismuth is generally a by-product of lead production, cadmium is associated with zinc production, gallium is acquired from aluminum production, indium is produced primarily from zinc recovery, and tellurium is commonly recovered as a by-product of copper refining. Direct mining for these elements would make them much more expensive and less abundant than they are today. Thus, the ability to recover rare elements from existing industrial metal processing is important to the supply of many elements. This section of JOM features an article by Shijie Wang on tellurium recovery from copper refining residue to illustrate how such recovery processes can occur.

\section{Toxic Element Control and Recovery}

The world has become much more protective of the environment and the health of individuals. Natural ores contain toxic elements that become part of industrial metal processing. These elements must be handled carefully during metal processing and disposed of properly to avoid unhealthy exposures during and after processing. Common examples of elements that pose significant environmental hazards include mercury, lead, chromium, and arsenic. Other elements that are not as widely discussed in a toxicity context are silver, cadmium, copper, and nickel. Radioactive elements such as uranium and those produced from nuclear reactors and nuclear decay products are also of great concern from an environmental perspective. Appropriate methods of controlling and removing such elements from industrial metal processing streams is vital to the safety of the industrial work force, and the appropriate disposal of such elements is critical to the environment and sustainability. An important example of toxic metal removal associated with metal processing is arsenic removal. A review of this important topic is provided by Larry Twidwell and Jay McCloskey.

\section{References}

1. http://en.wikipedia.org/wiki/Bingham_Canyon_Mine

Michael Free is a professor with the Department of Metallurgical Engineering at the University of Utah and is the advisor to JOM from the Hydrometallurgy and Electrometallurgy Committee of the Extraction \& Processing Division of TMS.

\section{Michael Free is a TMS Member!}

To read more about him, turn to page 10. To join TMS, visit www.tms.org/Society/Membership.aspx. 